\title{
A closer look at Moroccan EFL learners' use of language learning strategies from a qualitative perspective
}

\author{
Zahra EL AOURI \\ University Mohammed V, Rabat, Morocco
}

\begin{abstract}
This paper explores from a qualitative perspective the use of language learning strategies by Moroccan university EFL science students. Actually, it is part of a larger mixed method design research; however, the focus in this paper is just on the qualitative part so that a deep analysis of the informants' introspections on their language learning process is provided. The aim of this study is to delve deeply in students' use of language learning strategies and their motivation for learning English and how it relates to their strategy use. To collect data, 60 university students randomly drawn from six science-oriented majors participated in a semi-structured interview which focused on their motivation and their use of language learning strategies to learn English. Then, the interviews were first categorized in themes to have a clear picture of the informants' use of the different language learning strategies and the different types of their motivation to learn English, and second these themes were analyzed using the content analysis method. The results demonstrate that students use a variety of language learning strategies in different degrees and they exhibit different types of motivation to learn English. This study yields a number of implications both for pedagogical purposes and for further research.
\end{abstract}

Key words: language learning strategies - Moroccan EFL context - Moroccan EFL learners motivation - semi-structured interview

\section{Introduction}

Research on language learning strategies started to flourish with the emergence of the notion of "the good language learner" developed in the 1970s by Rubin (1975) and other researchers (Naiman, Frohlich, stern \& Todesco, 1978). On the basis of this notion, researchers tried to provide lists of strategies and other features deemed essential for good L2 learners. These strategies were further classified into different types and taxonomies depending on the learning context and on different 
learners' variables (age, gender, language aptitude, learning style, motivation, language proficiency...). Although many studies have been carried out in the field of language learning strategies, this area still lends itself to empirical research because language learning strategies remain a very conducive factor to language learning and many elements come into play when they are investigated such as the learning environment and the cultural context. Therefore, the present paper deals with the use of language learning strategies by Moroccan University EFL Science-oriented students in relation to their motivation from a qualitative perspective.

Before reporting the different components of the qualitative study conducted to this end, the first section below is devoted to a brief review of the literature related to this issue.

\section{Literature review}

The field of language learning strategies is anchored in different learning theories which form a theoretical framework within which these strategies can be studied. Those theories are the very perspectives from which each researcher examined language learning strategies and, hence, resulted in producing divergent definitions.

\section{The theoretical framework underlying language learning strategies}

In the present paper, the theoretical framework focuses on the cognitive model of learning and on the social-cognitive model of learning. The cognitive model of learning subsumes the information processing theory and schema theory:

Information processing theory is concerned with the thinking processes connected with learning and remembering information. These thinking processes include directing information from the shortterm memory to the long-term memory. Based on the information processing theory, learning requires processing new information by organizing it, elaborating on it and linking it to prior information stored in the mind. As a matter of fact, this is the function of cognitive strategies, which is analyzing, summarizing, inferencing, predicting...etc according to Chamot et al. (1999, p. 157). In this respect, as O'Malley and Chamot (1990) state "The role of learning strategies in the acquisition of information generally can be understood by references to the information processing framework for learning" ( $p$. 17). Therefore, information processing theory is very useful in understanding the role of learning strategies in acquiring new information. 
Schema theory postulates that learning takes place as human beings try to organize and understand phenomena, events, life experiences and knowledge in general in the light of prior knowledge. This prior knowledge is contained in organized and meaningful structures called schemata. These schemata, according to Chamot et al. (1999), help learners make predictions, visualize events, draw inferences, monitor comprehension and make summaries. Actually these are exactly the processes that learners go through while learning by using their schemata which are at the heart of learning strategies.

The cognitive model of learning, as mentioned above, emphasizes the cognitive involvement of the learner in the learning process. However, learning never takes place in isolation; instead learning occurs through interaction between individuals in a learning environment shaped by emotions, feelings and all the other affective components. Therefore, the social-cognitive theories developed by Bandura and Vigotsky can help understand learning at the socio-affective level.

Bandura's social-cognitive theory posits that people learn through observing the behavior of others in a given environment and all the personal factors involved are dynamic and mutually interactive. Another important aspect of Bandura's theory is personal motivation which is based on the concept of self-efficacy. That is, when learners carry out a task successfully, they develop the belief that they are capable of doing that kind of task. Hence, they become self-efficacious (1997, p. 238). Therefore, Bandura's social-cognitive theory underlies the socio-affective strategies of learning.

Vigotsky's (1978) theory is another theory underlying language learning strategies, and which is based on the premise that an individual's cognitive system is a result of social interaction; Vigotsky's theory is well known for the concept of the "zone of proximal development". This concept refers to the layers of knowledge or skill which are just beyond those which the learners are presently capable of coping with. This theory fits well with language learning strategies because when teachers help students to operate in their "zone of proximal development" while learning by providing them with support, the students can use a variety of thought processes such as analyzing, synthesizing and interacting with materials as well as with individuals. In this instance, students are doing nothing but employing language learning strategies. Thus, Vigotsky's social-cognitive theory also underlies language learning strategies. 


\section{Definition and taxonomy of language learning strategies}

Many well-known experts in the field of language learning strategies such as O'Malley et al. (1985b), Oxford (1990) and Rubin (1975) use the term strategy, yet there is still much controversy over this term. In other words, consensus is difficult to reach because some researchers use conflicting terminology such as learning behaviours (Politzer \& McGroarty, 1985), thoughts or beliefs (Weinstein \& Mayer, 1986), mental processes (O’Malley \& Chamot, 1990), behaviors or actions (Cohen \& Weaver, 1998; Oxford, 1990), tactics (Seliger, 1984), skills or operations or plans (Rubin, 1987), and techniques (Stern, 1992). These conflicting terms, most of the time, are used more or less synonymously with the term strategy.

From a cognitive perspective, many researchers have defined language learning strategies as mental processes. Nevertheless, a mental process cannot be easily described because it involves a higher level of abstraction. This is why Cohen and Weaver (1998) claim that a learning strategy should be distinguished from the non-strategic learning process. In the same line of thought, Macaro (2004) argues that "Strategies are not simply knowledge but contain a mental action that can be described. It is almost self-evident that the action component of a strategy ought to be describable by someone, especially a teacher or researcher" (p. 4).

Therefore, several researchers define language learning strategies according to their theoretical background. For instance, Rubin (1987) defines learning strategies as "any set of operations, plans, or routines, used by learners to facilitate the obtaining, retrieval, storage and use of information" (p.19). Rigney (1978) before Rubin (1987) defines in broad terms language learning strategies as "a set of operations used by the learner to aid the acquisition, storage and retrieval of information". Later, Stern (1983, p. 405) refers to language learning strategies as "particular forms of observable learning behaviour, more or less consciously employed by the learner." In 1992, Stern states in somewhat specific terms that "the concept of learning strategy is dependent on the assumption that learners consciously engage in activities to achieve certain goals and learning strategies can be regarded as broadly conceived intentional directions and learning techniques.” (1992, p.261)

It is clear that Stern (1983) stresses the observable and conscious side of language learning strategies whereas Rubin (1987) and Rigney (1978) consider strategies as mental processes because they refer 
to them as operations or plans that facilitate the assimilation and storage of input and then its retrieval for later use.

O'Malley and Chamot (1990) consider learning strategies as "the special thoughts or behaviors that individuals use to help them comprehend, learn, or retain new information” (p. 1). When O'Malley and Chamot (1990) refer to strategies as thoughts and behaviors which help learners understand and process new information, they clearly share the cognitive-based view of learning strategies with the other researchers before them such as Rubin (1987) and Stern (1983, 1992). Then in 2004, Chamot tried to restrict the definition of strategies when she refers to them - still within the cognitive theory - as "The conscious thoughts and actions that learners take in order to achieve a learning goal" (p. 14) hence, stressing the fact that strategies are conscious and goal-driven actions. Almost in the same year, Oxford (1990) shared the consciousness side of learning strategies with O'Malley and Chamot (1990), but she tried to specify the nature of learning strategies when she refers to them as "specific actions, behaviors, steps, or techniques students use - often consciously - to improve their progress in apprehending, internalizing, and using the L2" (p. 1).

From the abovementioned definitions, it seems that most researchers partially share some features of language learning strategies such as consciousness and the goal-driven nature of strategies although they treat them from different theoretical frameworks.

Based on the definitions provided by the early experts in the field of language learning strategies, Oxford (1990) developed one of the most comprehensive definitions of language learning strategies as: "operations employed by the learner to aid the acquisition, storage, retrieval, and use of information...; specific actions taken by the learners to make learning easier, faster, more enjoyable, more self-directed, more effective, and more transferable to new situations." (Oxford, 1990, p. 8)

Since there is total agreement in the literature that Oxford's (1990) definition is the most comprehensive to date (Oxford, 1999; Griffiths, 2003, 2006; Riazi \& Rahimi, 2005; Tam, 2013; Lee, 2010; Khamkhien, 2010), it is adopted as the working definition in the present paper.

Not only does how to define language learning strategies remain questionable in the field of strategy theory, but also how to classify them is apparently of great concern and disagreement. As stated by Oxford (1990), "there is no complete agreement on exactly what strategies are; how many strategies exist; how they should be defined, demarcated, and categorized; and whether it is - or ever will be - 
possible to create a real, scientifically validated hierarchy of strategies...Classification conflicts are inevitable." (p. 17).

Therefore, lack of clarity and agreement among researchers in this domain has caused inconsistencies and mismatches across existing taxonomies and classificatory systems developed by different researchers. In the present paper the focus is on Oxford's taxonomy (2001, p.359) which classifies strategies into two main categories: direct and indirect strategies which are in turn subdivided into six subcategories:

Direct strategies: 1) Cognitive strategies which enable the learner to manipulate the target language material in direct ways such as note-taking, reasoning, analyzing, summarizing, synthesizing, outlining ...etc 2) Metacognitive strategies which enable the learner to manage the learning process through identifying the learning style preferences, planning for L2 learning, gathering and organizing materials, arranging for learning, monitoring mistakes, evaluating the learning process ... etc 3 ) Memory strategies which enable the learner to link one L2 item or concept with another.

Indirect strategies: 1) Compensatory strategies which help the learner make up for missing knowledge such as guessing from context in listening and reading, using gestures ... etc 2) Affective strategies which enable learners to control their mood and anxiety level, talk about feelings, reward oneself for good performance, use positive self-talk and deep breathing ... etc 3) Social strategies which help the learner work with others and cooperate to understand the target language as well as the culture. For instance, learners ask questions, seek verification, ask for clarification ... etc

\section{Language learning strategies and motivation}

Many researchers examined L2 learners' use of language learning strategies in terms of the relationship between language learning strategies and learners' motivation to learn the L2. Oxford and Nyikos (1989), for example, highlighted the effects of motivation on strategy use by surveying 1,200 students studying various languages in a Midwestern American university in order to examine the kinds of language learning strategies the students reported using. In their study, the degree of expressed motivation was found to be the most influential among the variables affecting strategy choice examined.

Another study carried out by Chang and Huang (1999) confirmed that intrinsic motivation was found to significantly correlate with language learning strategies, namely with cognitive and metacognitive 
strategies. Pong's (2002) study, on the other hand, revealed that extrinsic motivation significantly correlates with cognitive and affective strategies and intrinsic motivation was reported to have a significant correlation with cognitive and metacognitive strategies which supports Chang and Huang's results.

In another study, Chen (2000) examined the relationship between motivation and deep-processing / surface-level strategies in the EFL environment and discovered a positive relationship between deepprocessing strategies and the motivation factors of betterment, acceptance, effort, and integration. However, surface-level strategies were found to significantly and positively correlate with the motivation factor of instrumentality.

According to the findings of these and other studies on the effects of motivation on strategy use, it can be concluded that motivation as a psychological construct do impact the use of language learning strategies, but in different ways. That is, different types of motivation influence different types of strategies in different learning contexts. Therefore, this paper will explore the relationship between motivation and the use of language learning strategies in the Moroccan EFL context from a qualitative perspective.

\section{Research methodology}

The present study is qualitative in nature since the main purpose is to delve deeply into the language learning strategies used by Moroccan university EFL Science-oriented students and their motivation to learn English. This is achieved through semi-structured interviews which are categorized into themes and analyzed using the content analysis method.

\section{Research objectives}

The main purpose of this study is concerned with investigating how Moroccan university EFL Science-oriented students use language learning strategies and how they are motivated to learn English. To realise this purpose, this research paper is geared towards achieving the following specific objectives:

1. The study tries to examine the types of strategies Moroccan University EFL Science students use in the learning process.

2. The study tries to examine the types of motivation Moroccan university EFL Science students exhibit in their English language learning process. 


\section{Research questions}

To meet the above-mentioned objectives, the following research questions are addressed:

1. What types of language learning strategies do Moroccan University EFL Science students tend to use more often?

2. What types of motivation do Moroccan university EFL Science students exhibit in their English language learning process?

\section{Participants}

The population targeted in this investigation is Moroccan university EFL Science-oriented students at the Faculty of Sciences, Mohammed V University - Rabat. Since this population does not constitute a homogeneous group, then stratified random sampling technique is applied in order to obtain a representative sample of 60 participants. Table 1 below demonstrates the demographic profile of the interviewees:

Table 1: Demographic information about the interviewees

\begin{tabular}{|c|c|c|c|}
\hline \multicolumn{2}{|c|}{ Variables } & \multirow{2}{*}{$\begin{array}{l}\text { Frequency } \\
10\end{array}$} & \multirow{2}{*}{$\begin{array}{l}\% \\
16.7\end{array}$} \\
\hline \multirow{7}{*}{ Academic major } & Computer science & & \\
\hline & Mathematics & 10 & 16.7 \\
\hline & Biology & 10 & 16.7 \\
\hline & Geology & 10 & 16.7 \\
\hline & Physics & 10 & 16.7 \\
\hline & Chemistry & 10 & 16.7 \\
\hline & Total & 60 & 100 \\
\hline \multirow[t]{3}{*}{ Gender } & Male & 30 & 50 \\
\hline & Female & 30 & 50 \\
\hline & Total & 60 & 100 \\
\hline \multirow{6}{*}{ Age in years } & 19 years old & 20 & 33.3 \\
\hline & 20 years old & 21 & 35 \\
\hline & 21 years old & 14 & 23.3 \\
\hline & 22 years old & 3 & 5 \\
\hline & 23 years old & 2 & 3.3 \\
\hline & Total & 60 & 100 \\
\hline \multirow[b]{3}{*}{ Languages spoken } & Arabic & 60 & 100 \\
\hline & Tamazight & 9 & 15 \\
\hline & French & 60 & 100 \\
\hline
\end{tabular}




\begin{tabular}{|c|l|l|l|}
\hline \multirow{4}{*}{$\begin{array}{c}\text { Language learning } \\
\text { experience in categories }\end{array}$} & English & 58 & 96.7 \\
\cline { 2 - 4 } & Other & 7 & 11.7 \\
\cline { 2 - 4 } & No experience & 1 & 1.7 \\
\cline { 2 - 4 } & Between 3 and 5 years & 45 & 75 \\
\cline { 2 - 4 } & Between 6 and 8 years & 12 & 20 \\
\cline { 2 - 4 } & 10 years & 2 & 3.3 \\
\cline { 2 - 4 } & Total & 60 & 100 \\
\hline \multirow{2}{*}{$\begin{array}{c}\text { Studying at a private } \\
\text { language center }\end{array}$} & Yes & 1 & 1.7 \\
\cline { 2 - 4 } & No & 59 & 98.3 \\
\hline & Total & 60 & 100 \\
\hline
\end{tabular}

As far as the demographic information of the 60 subjects who are involved in the interviews is concerned, the informants are equally distributed in terms of both academic major and gender (10 interviewees for each major and 30 for each sex category). Gender is also equally distributed within each academic major (five males and five females). The age range falls between 19 and 23 years; most of the interviewees are in their twenties.

From table 1 shows, one can notice that Moroccan university EFL Science-oriented students belong to a multilingual society as they speak different languages distributed between mother tongue and official languages. For instance, the 60 interviewees speak 100\% Arabic and French because Arabic is both their mother tongue (Moroccan Arabic) and their national and official language (Standard Arabic) while French is the main language in which they receive their university education. Also, $15 \%$ of the interviewees speak Tamazight as their mother tongue besides Moroccan Arabic, possessing, thus, a double mother tongue. For English, 96.7\% state that they speak English with varying degrees of proficiency whereas two interviewees confirm that they cannot speak English for reasons that they use to justify their statements.

As far as previous language learning experience is concerned, $75 \%$ of the interviewees report having three to five years experience while $20 \%$ report six to eight years experience and only two interviewees state that they had a language learning experience of ten years. Again as an exception, one interviewee state that he had no experience in studying English at all and justified his statement during the interview. To the question as to whether they take extra courses at a private language center, $98.3 \%$ state that they did not while only one interviewee confirm that he was taking courses at the British Council. 


\section{Data collection instrument}

Since interviews have been acknowledged as valuable research instruments because they provide specific and personalized information on many types of language learning strategies which would not be available through classroom observations or other methods, as Oxford and Burry-Stock (1995) claim, a semi-structured interview is used to collect data for the present study. The choice of the semistructured interview is also justifiable by the fact that it can provide depth of explanation using probes and prompts, something which cannot be achieved with questionnaires alone. Furthermore, semistructured interviews are quite similar to open-ended questions used in questionnaires which allow the interviewees to react with more freedom.

The semi-structured interview in this study consists of three sections. The first section contains six questions on biographical data about the interviewees including their names, age, academic major, years of English study, languages spoken and whether the interviewee studies at an English school at the current time. The second section concerns 12 questions about the interviewees' motivations for and attitudes towards studying English. The third section consists of 22 questions that allow the interviewees to reflect and introspect on the language learning strategies they use while learning English. To account for reliability and validity of the interview, the interviewing was conducted in the subjects' L1 (Moroccan Arabic) for fear that their limited level of proficiency in English would have hindered their ability to express themselves with ease and reveal valuable information to serve the purpose of the study. This also helped avoid any embarrassment or anxiety the informants would have felt having to speak a language they do not master yet, especially that most of them were taking part in such an interview for the first time.

\section{Data collection and analysis procedures}

The researcher kindly asked for volunteers for the interview, and actually most students were collaborative in accepting to be involved in the interviews. Many students wanted to participate in the interview provided that they use their L1 (Moroccan Arabic). The researcher accepted their condition and told them that their anonymity would be secured and no one other than the researcher would have access to their recorded data. The researcher selected 60 subjects, 10 students from each academic major (five females and five males) to be interviewed. A whole month was devoted to conducting interviews. The recording sessions were scheduled at the end of the interviewees' English classes at mid-day because this was a suitable time for both the researcher and the interviewees. A Digital Voice Recorder machine was used to record the interviews which were conducted in the 
participants' L1 Moroccan Arabic. The researcher asked the questions and the interviewees responded freely while the researcher was listening, recording, probing and prompting when necessary until the participant stops. The interviewees seemed comfortable and did not show any anxiety, which helped in eliciting interesting information that can be valid and reliable. Most interviews took between 20 and 25 minutes and a few of them took up to 30 minutes.

After collecting data using a qualitative method, the semi-structured interviews are first transcribed and translated into English to facilitate quoting interviewees' testimonies. Second, the interviews are categorized into themes to have a clear picture of the informants' use of the different language learning strategies and the different types of their motivation to learn English. Third, these themes are analyzed using the content analysis method.

\section{Findings and discussion}

This section is devoted to the presentation of the findings obtained after transcribing the 60 interviews and extracting the main themes and subthemes which the transcriptions yield. In parallel with the presentation of the findings, the researcher tries to provide a qualitative analysis and discussion of Moroccan University EFL Science-oriented students' reported use of LLSs and their motivational orientations.

\section{Emerging types of strategies in the semi-structured interview}

In the semi-structured interview, all the six types of strategies (memory, cognitive, compensation, metacognitive, affective, and strategies) dealt with in the present study are heavily used by the 60 interviewees as reflected in the varying percentages drawn from their introspections in the following tables.

Table 2: Memory strategies

\begin{tabular}{|l|l|l|c|c|}
\hline $\begin{array}{l}\text { Strategy } \\
\text { category }\end{array}$ & \multicolumn{2}{|c|}{ Subcategory } & Frequency & $\%$ \\
\hline \multirow{3}{*}{\begin{tabular}{l} 
Creating mental linkages \\
\cline { 3 - 5 }
\end{tabular}} & $\begin{array}{l}\text { Associating and } \\
\text { grouping }\end{array}$ & 37 & 61.7 \\
\cline { 3 - 5 } & $\begin{array}{l}\text { Contextualizing new } \\
\text { words }\end{array}$ & 40 & 66.7 \\
\cline { 2 - 5 } & Using imagery & Visual memorization & 30 & 50 \\
\cline { 2 - 5 } & Using mnemonics & 4 & 6.7 \\
\hline
\end{tabular}




\begin{tabular}{|l|l|l|c|c|}
\hline \multirow{3}{*}{$\begin{array}{l}\text { Memory } \\
\text { strategies }\end{array}$} & \multirow{2}{*}{ Reviewing } & Reviewing vocabulary & 22 & 36.7 \\
\cline { 2 - 5 } & \multirow{3}{*}{ Word retrieval } & Revising lessons & 58 & 96.7 \\
\cline { 3 - 5 } & Rote learning & 27 & 45 \\
\cline { 3 - 5 } & $\begin{array}{l}\text { Parsing and categorizing } \\
\text { words }\end{array}$ & 10 & 16.7 \\
\hline
\end{tabular}

As far as Memory strategies are concerned, creating mental linkages, especially associating and grouping are much used by the interviewees. For instance, a female interviewee from Mathematics major says: "When I hear or see a new word, I try to relate it to something else I've heard or seen on $T V$ or read somewhere. 'Therefore, the interviewee tries to create a mental linkage between what she learns as new information and what she already knows. Another memory strategy which the participants report they make use of more frequently is visual memorization to remember new words as illustrated by the following statement from a male interviewee from Physics major: "I link the new word with its image or I just try to locate where I've seen the word." One of the memory strategies related to rote learning is somehow used by the interviewees as they confirm that they resort to this strategy when they have difficulty retaining vocabulary, expressions or grammatical structures. An example is the following statement of a male interviewee from Computer Science when asked whether he tries to learn things by heart: "Of course, I try to learn by heart new words, expressions and verbs. " In addition, the memory strategy related to contextualizing new words is heavily used by the interviewees. A female interviewee from Biology says: "I try to use the new word in a sentence so that I can remember its meaning and how it is used and I try to use this new word often."

This dependency on memory strategies can be due to students' actual stage of learning. It maybe that these students are at an early stage of their English learning and, hence, they need to use various memory strategies to encode the new input they receive in order to stock it in their short-term memory before transferring it to the long-term memory so that they can retrieve it later. This is one of the underlying principles of the information processing theory on which language learning strategies draw as O'Malley and Chamot (1990) state "The role of learning strategies in the acquisition of information generally can be understood by references to the information processing framework for learning" (p.17). Nonetheless, despite the usefulness of memory strategies for stocking information in memory to be retrieved later, they do not involve deep comprehension on the part of the learner. Another explanation is related to the vocabulary size of the students; they may have a shortage of vocabulary so they resort to different memory strategies to build their own vocabulary repertoire. Furthermore, the nature of the Moroccan educational system which is based on memorization as a 
technique for acquiring knowledge, especially in primary school, can explain Moroccan students' use of memory strategies because they are already used to various memorizing techniques.

Table 3: Cognitive strategies

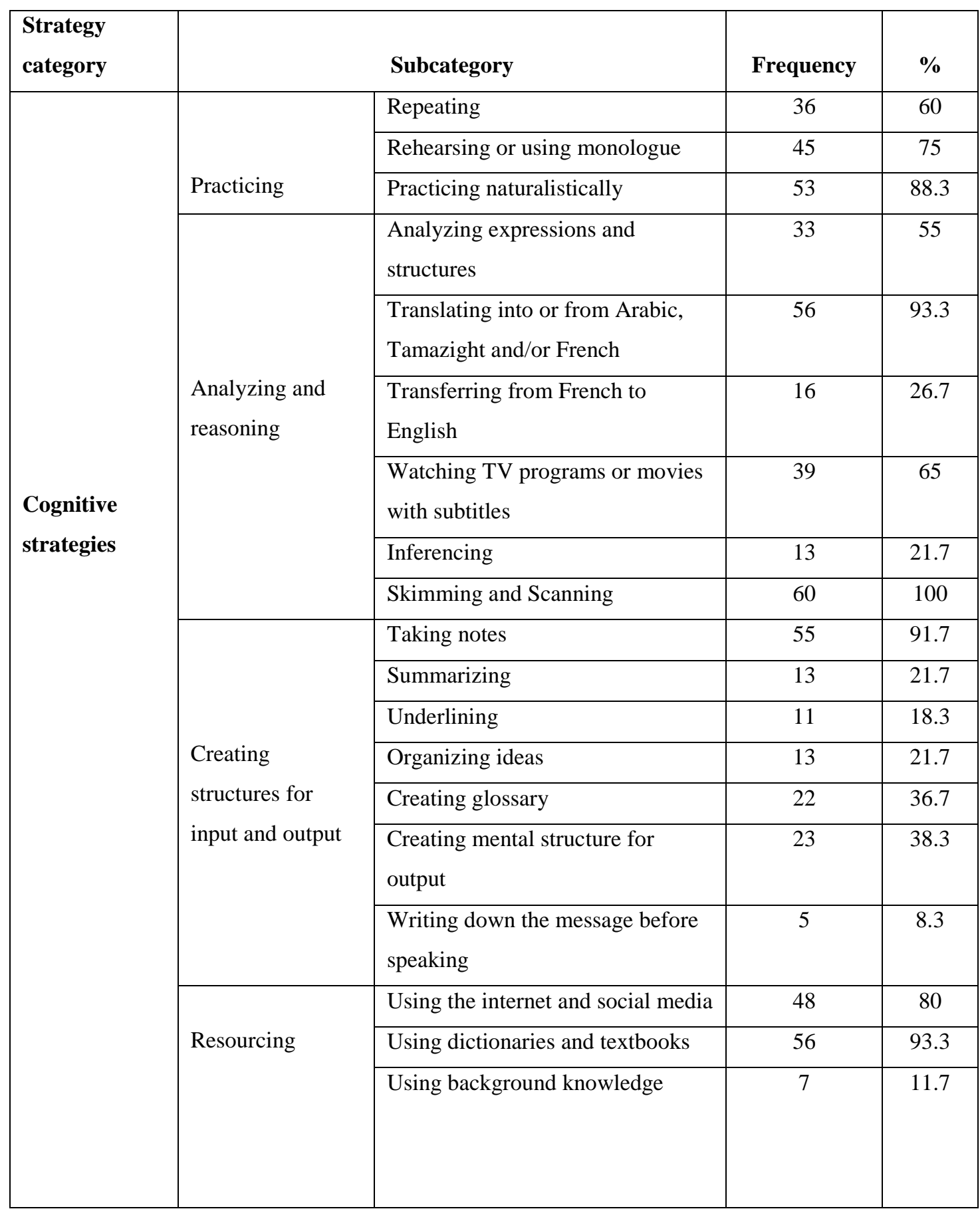

Cognitive strategies are also used a lot by the informants, especially the analyzing and reasoning strategy. This is reflected in the response of a male interviewee from Geology major who says: " $I$ always rely on the subtitles to understand otherwise I wouldn't understand anything because I can retain only the end of what they say as they speak very fast. Recently, I tried to listen first and then after a while read the subtitle to get used to listening without reading the translation and gradually 
get rid of subtitles." Two cognitive strategies are also reported which are creating structures for input and output, especially summarizing and organizing ideas. A female student from Chemistry major reports that "Before each session, I try to revise the lesson of the previous session. I summarize the lesson and I try to remember the rules. " Therefore, this female interviewee confirms that she practices summarizing strategies when she is probed for the use of reviewing strategies. However, when another male interviewee majoring in Chemistry too is asked about writing, he clearly admits that he seldom practices writing and organizing ideas in output as he says: "It depends on the person I'm writing to; if the person uses English, I'm obliged to do so too. Sometimes, I use only some English words while chatting in French or Moroccan Arabic even."

According to the findings of the present study, Moroccan university EFL Science students make great use of a wide repertoire of cognitive strategies such as practicing, analyzing and reasoning or structuring input and output because the learning of any new language requires the learners to use cognitive processes to manipulate input. This is the case of the present study participants who try to reason out the language by constructing a formal model of the linguistic system of English in their minds on the basis of analysis and comparison, and then come up with general rules to apply them in new situations. Another factor which may explain the present study participants' heavy reliance on cognitive strategies is their high motivation to learn English. As they are both instrumentally and integratively motivated, these students resort to a variety of cognitive strategies to analyze the input they receive and try to structure it in a way that it can be transformed into an output. This can be a valid argument since the relationship between motivation and LLSs in general is circular in the sense that a strong motivation may lead to a greater use of strategies and the latter may cause students' motivation to increase. That is, when students are highly motivated, they use more LLSs which improve their language performance and in turn increase their motivation. In addition, the use of cognitive strategies can be explained by the fact that Moroccan students belong to a multilingual society as they speak at least two languages. Through their exposure to two languages - Arabic and French - as formal vehicles of learning in the educational system, they may have acquired a substantial repertoire of different learning strategies including the cognitive ones. These strategies previously used in these two languages can be transferable to learning English.

Table 4: Compensation strategies

\begin{tabular}{|l|c|l|c|c|}
\hline $\begin{array}{l}\text { Strategy } \\
\text { category }\end{array}$ & \multicolumn{2}{|c|}{ Subcategory } & Frequency & \% \\
\hline \multirow{3}{*}{} & Guessing from context & 35 & 58.3 \\
\cline { 2 - 4 } & Using key words & 10 & 16.7 \\
\hline
\end{tabular}




\begin{tabular}{|c|c|c|c|c|}
\hline \multirow{10}{*}{$\begin{array}{l}\text { Compensation } \\
\text { strategies }\end{array}$} & Guessing & $\begin{array}{l}\text { Guessing meaning of one word } \\
\text { from adjacent words }\end{array}$ & 3 & 5 \\
\hline & \multirow{9}{*}{$\begin{array}{l}\text { Overcoming limitations in } \\
\text { speaking or writing }\end{array}$} & Code-switching & 35 & 58.3 \\
\hline & & Using gestures and mimicry & 54 & 90 \\
\hline & & Seeking help from interlocutor & 27 & 45 \\
\hline & & Drawing & 13 & 21.7 \\
\hline & & $\begin{array}{l}\text { Avoiding communication and } \\
\text { keeping silent }\end{array}$ & 10 & 16.7 \\
\hline & & Approximating the message & 23 & 38.3 \\
\hline & & Message abandonment & 3 & 5 \\
\hline & & $\begin{array}{l}\text { Using circumlocution and } \\
\text { synonyms }\end{array}$ & 18 & 30 \\
\hline & & Simplifying and rephrasing & 27 & 45 \\
\hline
\end{tabular}

Compensation strategies which are used to overcome linguistic limitations in speaking or writing are used to some extent by the interviewees in the form of circumlocution or synonyms that the students resort to in case they do not know how to say something in English. This extract from an interview with a female informant majoring in Mathematics shows an instance of circumlocution: "I try to use description of what the word means if I don't have the correct word or I take the French origin of the word I intend to use and give it an English form either in pronunciation or spelling." Another male informant from Biology resorts to synonyms in case he does not know the exact word he wants to use, saying "I try to find synonyms for the words which are unclear or I rephrase the sentence so that the other can understand me." The use of circumlocution and synonyms as compensation strategies can be a good sign that the subjects of the current study are progressing in their learning of English. They do their best to keep learning and achieve their goal in communication which is to make their interlocutor in either speaking or writing understand their message despite the language difficulties or even linguistic gaps they experience.

The interviewees heavily resort to gestures and mimicry as compensation strategies if they lack the exact words to express themselves. This is an example of a male informant specialized in Physics who resorts to gestures as a solution for maintaining communication; he says: "I try to use all my abilities; I try to speak in English and use gestures at the same time. If I really can't do it in English, I draw it." The use of gestures as a compensation strategy is quite acceptable in different communicative situations and much expected in a foreign language classroom because communication does not happen only through verbal means, but non-verbal tools are also involved. Therefore, the sample of this study relies heavily on gestures to compensate for their lack of linguistic 
knowledge in English and to sustain their communication with non-verbal means in order to avoid any communication breakdown.

Generally speaking, Moroccan students resort to a wide range of compensation strategies both in comprehension and production to make up for their missing information in English. This heavy reliance on compensation strategies can be due to different factors. One of these factors which initiate the use of different strategies including compensation is the students' high motivation. That is, since students are highly motivated, they try to explore different ways to learn English and put what they have learnt into practice. Therefore, they exploit different ways such as gestures, drawing, circumlocution, paraphrasing ...etc to participate in different communicative situations such as conversations and productive tasks like writing. Another possible reason for this heavy use of compensation strategies is that Moroccan university EFL Science students are strongly engaged in grammar- and vocabulary-based learning at the expense of speaking or writing which are the two productive skills in language learning. In other words, Moroccan students learn in a passive environment which transmits English linguistic knowledge from books or teachers to the brains of students without providing them with an active and authentic context so that they can put this linguistic knowledge into practice. This is why when students find it difficult to transfer their knowledge of grammar and vocabulary to real practice, they resort to either nonverbal tools and strategies such as gestures or circumlocution to make up for their deficiencies in language skills. Also, the fact that these students may have a strong desire to persevere in learning and using English can be a plausible explanation for their use of compensation strategies. Actually, with the help of these strategies used both in comprehension and production tasks, students are able to produce spoken and written expressions, phrases and even sentences in English although they have certain deficiencies in language skills. The essential goal for these students is to continue using and learning English by all means. On the whole, compensation strategies seem to be crucial for students, especially at an early stage of learning, to help them progress in the learning process and become better language learners.

Table 5: Metacognitive strategies

\begin{tabular}{|l|c|l|c|c|}
\hline $\begin{array}{l}\text { Strategy } \\
\text { category }\end{array}$ & \multicolumn{2}{|c|}{ Subcategory } & Frequency & $\%$ \\
\hline \multirow{2}{*}{} & & $\begin{array}{l}\text { Linking with background } \\
\text { knowledge and already } \\
\text { known material }\end{array}$ & 9 & 15 \\
\cline { 3 - 5 } & & $\begin{array}{l}\text { Focusing and paying } \\
\text { attention }\end{array}$ & 33 & 55 \\
\hline
\end{tabular}




\begin{tabular}{|c|c|c|c|c|}
\hline \multirow{9}{*}{$\begin{array}{l}\text { Metacognitive } \\
\text { strategies }\end{array}$} & Centering learning & $\begin{array}{l}\text { Delaying speech } \\
\text { production to focus on } \\
\text { listening while mentally } \\
\text { organizing and } \\
\text { structuring ideas }\end{array}$ & 23 & 38.3 \\
\hline & \multirow{5}{*}{ Planning learning } & $\begin{array}{l}\text { Discovering about } \\
\text { language learning }\end{array}$ & 53 & 88.3 \\
\hline & & Organizing input & 19 & 31.7 \\
\hline & & $\begin{array}{l}\text { Setting goals and } \\
\text { objectives }\end{array}$ & 58 & 96.7 \\
\hline & & Scheduling learning & 43 & 71.7 \\
\hline & & $\begin{array}{l}\text { Seeking practice } \\
\text { opportunities }\end{array}$ & 60 & 100 \\
\hline & \multirow{3}{*}{ Evaluating learning } & Evaluating oneself & 56 & 93.3 \\
\hline & & $\begin{array}{l}\text { Monitoring one's } \\
\text { progress }\end{array}$ & 47 & 78.3 \\
\hline & & $\begin{array}{l}\text { Seeking teacher's } \\
\text { feedback }\end{array}$ & 23 & 38.3 \\
\hline
\end{tabular}

As far as metacognitive strategies are concerned, the interviewees make average use of focusing and paying attention which is subsumed under centering learning strategy. For example, a male informant from Mathematics major shows how he pays attention to how English is used in movies when he says: "When I'm watching a film for instance, I tend to read the subtitles because they help me pick up new vocabulary, but I try to pay attention to what they say and how they say it." Metacognitive strategies like centering learning, thus, seem to help Moroccan students reflect on their learning process since they try to pay attention and focus on the activities they are engaged in whether inside or outside class such as watching an English movie. Therefore, the students use these metacognitive strategies to develop a sense of self-directed and autonomous learning. In this regard, O'Malley and Chamot (1990) state "students without metacognitive approaches are essentially learners without direction or opportunity to plan their learning, monitor their progress, or review their accomplishments and future learning directions" (p. 8).

Among the metacognitive strategies investigated is monitoring one's progress in learning English. This is what a male interviewee specialized in Physics says: "I feel that my level should be improved so that I can avoid these mistakes." Another metacognitive strategy which is seeking practice opportunities is used by all the interviewees. The following response from a female informant majoring in Geology shows how these interviewees make use of different opportunities to improve 
their level in English. She says: "I try to watch a lot of TV programs and movies in English; use English websites and the internet; and speak English with people a lot."

According to the findings of the present study, metacognitive strategies, like cognitive strategies, are of paramount importance to learners. They seem to be used nearly at the same rate. This is quite understandable since metacognitive strategies represent the knowledge students possess about cognitive processes. That is, metacognitive strategies are the executive control which students have over their learning process in the form of centering, planning and evaluating their learning. Again, it may be plausible to argue that Moroccan university EFL Science students' previous experience in learning Arabic and French may have triggered their development of metacognitive strategies, which they transfer to English learning, as found in the present study. On the whole, the use of metacognitive strategies, as Anderson (2002) confirms, ignites students' thinking and helps them move to higher learning and attain better performance. Moreover, metacognitive strategies are central to the language learning process because once students know how to regulate their own learning through the use of different strategies, the speed of language learning becomes faster (Anderson, 2003).

Table 6: Affective strategies

\begin{tabular}{|c|c|c|c|c|}
\hline $\begin{array}{l}\text { Strategy } \\
\text { category }\end{array}$ & \multicolumn{2}{|c|}{ Subcategory } & Frequency & $\%$ \\
\hline \multirow{10}{*}{$\begin{array}{l}\text { Affective } \\
\text { strategies }\end{array}$} & \multirow{6}{*}{ Lowering anxiety } & Breathing deeply & 7 & 11.7 \\
\hline & & Relaxing & 6 & 10 \\
\hline & & Calming down & 8 & 13.3 \\
\hline & & Keeping silent for a while & 20 & 33.3 \\
\hline & & Smiling or laughing & 2 & 3.3 \\
\hline & & Avoiding panic & 16 & 26.7 \\
\hline & \multirow{4}{*}{ Encouraging oneself } & Positive self-talk & 15 & 25 \\
\hline & & Rewarding oneself & 14 & 23.3 \\
\hline & & Motivating oneself & 47 & 78.3 \\
\hline & & Satisfaction with oneself & 57 & 95 \\
\hline
\end{tabular}

Affective strategies are used to a limited extent by the informants. For example, to lower anxiety, they try to breathe deeply, calm down, keep silent for a while and smile or laugh. However, the informants tend to use more self-motivating strategies, develop self-satisfaction and talk positively to themselves instead of rewarding themselves when they do well in English. A female interviewee from Computer Science provides the following response to the question "Do you reward yourself when you do well in English? How do you do that?" She says: "Maybe I reward myself without being aware 
of it; in fact, I don't remember an instance when I did this. What I'm sure of is that when I get a good mark or do well in English I talk to myself positively."

It is important to note that the participants do not seem to resort to affective strategies a lot as revealed in the current study. This may be due to cultural reasons as Moroccan students are not used to rewarding themselves when they perform well or revealing their feelings to other people while learning. In addition, teachers tend to neglect the affective side of learners. However, this cultural factor remains speculative and needs further research to prove its effect on the use of affective strategies. Quite interestingly, however, the subjects of the present study do use some self-motivating strategies like the positive self-talk or self-encouragement. This may be explained by their high motivation to achieve a good level of proficiency. According to Oxford (1990), this self-motivation or self-encouragement is much better than the appreciation that comes from other people because it stems from an intrinsic motivation of the student.

Table 7: Social strategies

\begin{tabular}{|c|c|c|c|c|}
\hline Strategy category & & Ibcategory & Frequency & $\%$ \\
\hline \multirow{7}{*}{ Social strategies } & \multirow[b]{2}{*}{ Asking questions } & $\begin{array}{l}\text { Asking for clarification or } \\
\text { verification }\end{array}$ & 29 & 48.3 \\
\hline & & Asking for correction & 13 & 21.7 \\
\hline & \multirow{2}{*}{$\begin{array}{l}\text { Cooperating with } \\
\text { others }\end{array}$} & Cooperating with peers & 40 & 66.7 \\
\hline & & Asking for help from peers & 33 & 55 \\
\hline & \multirow{3}{*}{$\begin{array}{l}\text { Empathizing with } \\
\text { others }\end{array}$} & $\begin{array}{l}\text { Developing cultural } \\
\text { understanding and awareness }\end{array}$ & 53 & 88.3 \\
\hline & & $\begin{array}{l}\text { Becoming aware of others' } \\
\text { way of thinking and feeling }\end{array}$ & 47 & 78.3 \\
\hline & & $\begin{array}{l}\text { Socializing online with } \\
\text { foreigners }\end{array}$ & 38 & 63.3 \\
\hline
\end{tabular}

Social strategies are used by half of the interviewees under the strategy asking for clarification or verification. This is what a male informant majoring in Mathematics states when asked "Do you often listen to people (like tourists on a train or on the street for example) talking in English? What do you do to help yourself understand?" The Interviewee replies: "It is difficult for me to understand them if they are speaking fast; but if they are talking to me, I ask them to slow down so that I can understand them." 
Social strategies are considered one of the useful tools to practice communication in English in terms of interpersonal behaviors such as asking questions, asking for clarification and verification or asking for help. Interestingly, Moroccan university EFL Science students in the current study do use social strategies although they belong to an EFL context in which communication in English is very limited given the little chance they have to use authentic English. To make up for this lack of authentic input, they try to look for opportunities to involve themselves in real communication such as talking to tourists or socializing with foreigners through social media.

Another social strategy which is cooperating with peers is used at an average level by the interviewees. The following female informant from Physics major confirms this cooperation strategy when she says: "Yes, we study English as a group, especially when exams are close."

Resorting to social strategies, such as cooperating with peers while learning English, can be explained by the students' familiarity with this strategy in their different content classes. In the English class, they use cooperation strategies like working with peers on challenging tasks or asking proficient peers for help in order to facilitate their learning. These strategies do not only help them improve their level in English, but they help them gain self-worth and social acceptance within their learning environment as well. Developing cultural understanding and awareness under the social strategy of empathizing with others is heavily used by of the informants. Furthermore, they report that becoming aware of other people's ways of thinking and feeling as a social strategy is used along with socializing online with foreigners. In fact, social strategies do not only help students to work with others and improve their language performance, but they help them develop an understanding of the target culture as well because as Oxford (1990) states "language is a form of social behavior". Therefore, it is impossible to disentangle language from social interaction which is used as a vehicle for different cultural behaviors. Thus, as the findings of the present study demonstrate, the participants rely on empathizing as a social strategy to understand the culture of foreigners and their ways of thinking and feeling. This empathy which students develop with regard to the foreign language and culture can help them succeed in learning English.

There are at least two plausible explanations for the use of social strategies by the students in the current study. First, these students may prefer to use social strategies to escape the passive grammar and vocabulary centered classes in which there is little space for speaking and real communication. Moroccan students try to look for some authentic situations in which they can use their English for communicative purposes. Second, the students' unlimited exposure to the internet, different multimedia sources and social networking such as Facebook may be a reason for the use of a variety 
of social strategies. These NTIC (New Technologies of Information and Communication) tools provide students with more English input and permit them to engage in social interaction by socializing with foreigners online and empathizing with different foreign cultures. Therefore, students are encouraged to use social strategies inside and outside class to practice their English because they are aware that they belong to an EFL context which does not provide them with rich input of English and authentic opportunities for real communication.

\section{Emerging types of motivation in the semi-structured interview}

Four types of motivation which are integrative, instrumental, intrinsic and extrinsic motivation are reflected in the interviewees' introspections with varying degrees.

Table 8: Integrative motivation

\begin{tabular}{|l|l|c|c|}
\hline $\begin{array}{l}\text { Type of } \\
\text { motivation }\end{array}$ & \multicolumn{1}{|c|}{ Elements of each type } & Frequency & $\%$ \\
\hline \multirow{5}{*}{ Integrative } & $\begin{array}{l}\text { Usefulness of English for cultural integration and } \\
\text { exchange }\end{array}$ & 39 & 65 \\
\cline { 2 - 4 } & $\begin{array}{l}\text { Usefulness of English for communicating and } \\
\text { socializing online with people }\end{array}$ & 48 & 80 \\
\cline { 2 - 4 } & $\begin{array}{l}\text { Usefulness of English for getting acquainted with } \\
\text { the Anglo-Saxon culture, literature and civilization }\end{array}$ & 12 & 20 \\
\cline { 2 - 4 } & $\begin{array}{l}\text { Usefulness of English for cultural openness and } \\
\text { knowing foreigners' ways of thinking }\end{array}$ & 8 & 13.3 \\
\hline
\end{tabular}

As far as motivation is concerned, the results of the present study indicate that Moroccan university EFL Science students are inclined towards integrative motivation. The majority of the interviewees find learning English useful for communicating and socializing online with people. This is reflected in the following response by a female interviewee majoring in Biology: "Umm, I think English will be useful in my life in general because English is used a lot in our life; for example, if I'm online chatting with someone and the person speaks only English, I won't find any problems in communication."

In the light of the findings concerning motivation, Moroccan university EFL Science students in the present study are inclined towards integrative orientation in their learning of English because as Gardner (1985) stresses "languages are unlike any other subject taught in a classroom in that they involve the acquisition of the skills or behavior patterns which are characteristic of another cultural 
community" (p.146). Actually, students who learn English with an integrative goal in mind try to capitalize on all practice opportunities and have a strong desire to reach a high proficiency level in English. This is what Moroccan students in this study attempt to do when they seek communication opportunities with foreigners and try to know about their cultures and civilization. Not only are Moroccan university EFL Science students interested in communication with foreigners, but they are interested in cultural integration and exchange as well since most of them state that learning English is useful for these reasons. This is clearly expressed by this female informant from Physics major who says "The usefulness of English in my life in general is reflected in communication with people from different cultures. I intend to continue my studies in the U.S. so English will be useful for me to integrate in the American society."

It should be important to note that this strong desire to integrate in the target language community and this enthusiasm to learn about their culture, literature and civilization can be a good reason why Moroccan university EFL Science students use different language learning strategies. As stated by Bonney et al. (2008) "students with an integrative motivation are more interested in becoming immersed in a culture, and increase their capabilities of interacting with native speakers. If students are able to compensate for any lack of knowledge they have about a language, and are able to troubleshoot these problems by thinking of synonyms, asking native speakers to slow down or repeat themselves, or make gestures to help communicate their thoughts, they may be more likely to successfully communicate and interact with native speakers." (p. 8).

Other interesting aspects of integrative motivation are the usefulness of English to get acquainted with the Anglo-Saxon culture, literature and civilization and the usefulness of English for cultural openness and knowing about foreigners' ways of thinking. These two aspects of integrative motivation are stated by the interviewees. For instance, a female informant majoring in Physics responds: "I like very much to learn how to communicate and I also like the English literature, especially the British one. They have interesting books and writings." Another female informant majoring in Mathematics also confirms that she appreciates the English language and the AngloSaxon culture, literature and civilization when she says: “..... apart from studies, English is important as a culture and I like many things in the language. For example, there are a lot of novels and stories in English that I would like to read and also there are many thinkers whose writings are in English." 
It is likely that this zeal of the present study participants for integrative motivation, though they study in an EFL context, stems from the fact that they associate a global status with English. That is, they consider English as an international language and do not closely associate it with its native speakers. However, there is a need for further research to shed more light on this aspect.

Table 9: Intrinsic motivation

\begin{tabular}{|l|l|c|c|}
\hline $\begin{array}{l}\text { Type of } \\
\text { motivation }\end{array}$ & \multicolumn{1}{|c|}{ Elements of each type } & Frequency & $\%$ \\
\hline \multirow{5}{*}{ Intrinsic } & $\begin{array}{l}\text { Enjoying learning all aspects of English and having a } \\
\text { strong desire to use it like native speakers }\end{array}$ & 56 & 93.3 \\
\cline { 2 - 4 } & Ambition and perseverance to learn and master English & 57 & 95 \\
\cline { 2 - 4 } & Setting goals and objectives for learning English & 5 & 8.3 \\
\cline { 2 - 4 } & Learning English to develop one's competences & 1 & 1.7 \\
\cline { 2 - 4 } & Learning English to satisfy one's desires and pleasures & 2 & 3.3 \\
\cline { 2 - 4 } & Learning English is empowering and boosts one's self- & 13 & 21.7 \\
& esteem & & \\
\hline
\end{tabular}

Concerning intrinsic motivation, only two aspects are heavily reported by the interviewees, but the other aspects are reported with varying degrees. For instance, almost all the informants highly report the ambition and perseverance to learn and master English. A male interviewee from Computer Science major makes the following response: "Umm......absolutely, I'll continue learning English until I get my TOEFL."

The fact that Moroccan university EFL Science students' intrinsic motivation is generally high can be attributed to their desire to be successful and autonomous. In other words, these students are interested in learning the language for its own sake and they want to attain enough proficiency to pursue higher level studies. In this way, they will feel a sense of accomplishment and autonomy in their learning. According to Self-Determination theory, students who are intrinsically motivated are usually high achievers and autonomous because they are able to perform well and succeed as there is no outside pressure on them. On the other hand, they have an inside driving force which instills some kind of self-confidence in them to learn on their own.

Another aspect of intrinsic motivation is reported by almost all the informants who state that they enjoy learning all aspects of English and they have a strong desire to be like native-speakers. As an example, a female informant majoring in Biology clearly expresses this strong desire when she 
responds: "Frankly, I like to learn all the components of English." In fact, the semi-structured interview yields interesting aspects of intrinsic motivation. For instance, some of the informants state that they learn English because they find it empowering and it boosts their self-esteem and others say that they learn English to satisfy their own pleasures and desires. For instance, a male interviewee from Computer Science expresses how learning English satisfies his own pleasures and desires when he says: "Yes it is very important because it is the language of the world; it is accessible almost to everybody. Besides, people who learn different languages can be safe against Alzheimer because they keep changing languages which makes their minds process different codes and their brain cells are all the time alive and elastic." This intrinsic orientation in learning English can also be due to the Moroccan students' desire to create a good self-image and achieve some kind of self-worth in society. They want to avoid loss of face in front of the other when they are in a situation that requires the use of English. Therefore, it can be said that intrinsic motivation is much related to the personality of the learners since it stems from within their selves and, hence, this type of motivation can be enduring unlike other types which are sporadic.

In short, intrinsic motivation is somehow similar to the integrative orientation since both types are initiated from inside the students. That is, integrative motivation is driven by an internal force to identify with the target language community and explore their culture through learning English; intrinsic motivation likewise is driven by the same force to learn English for the mere enjoyment of learning and to develop a high self-esteem and some degree of self-confidence. Thus, both types seem to be stable and can foster successful learning.

Table 10: Instrumental motivation

\begin{tabular}{|c|c|c|c|}
\hline $\begin{array}{l}\text { Type of } \\
\text { motivation }\end{array}$ & Elements of each type & Frequency & $\%$ \\
\hline \multirow{6}{*}{ Instrumental } & Importance of English for one's career and future & 59 & 98.3 \\
\hline & $\begin{array}{l}\text { Need of English for utilitarian purposes such as } \\
\text { solving practical problems in life in general }\end{array}$ & 30 & 50 \\
\hline & $\begin{array}{l}\text { Importance of English for further studies and } \\
\text { scientific research }\end{array}$ & 42 & 70 \\
\hline & $\begin{array}{l}\text { Usefulness of English for getting information in } \\
\text { one's field of study on the internet }\end{array}$ & 37 & 61.7 \\
\hline & Learning English to be well-educated and cultured & 7 & 11.7 \\
\hline & $\begin{array}{l}\text { Usefulness of English for watching movies, the } \\
\text { news, TV programs and listening to songs }\end{array}$ & 56 & 93.3 \\
\hline
\end{tabular}


For instrumental motivation, the present study reveals that Moroccan university EFL Science students are highly instrumentally motivated. For example, almost all the interviewees say that learning English is important for their career and future. A male informant from Chemistry major responds in the following way: "....English can serve either in applying for a job or in the job interview. For example, if I master English, I may have an advantage in getting a job over another candidate who is not good at English." Actually, the informants seem to be highly instrumentally motivated for utilitarian purposes. A possible reason for this could be that they believe English will form the basis for their future careers as it can secure job opportunities for them. This instrumental orientation is not surprising given the globalization process and the importance of English for job opportunities in the global job market. Furthermore, the usefulness of English for watching movies, TV programs, the news and listening to songs receives the lion's share in the interview since all the informants state that they need English for such purposes. A male interviewee majoring in Physics clearly expresses himself saying: "Yes, I watch English movies a lot and listen to songs in English and I read their lyrics so as to understand their meaning. I also watch scientific documentaries in English to follow what is happening in science and technology."

Generally speaking, students have different needs and interests which generate this instrumental inclination to learn English. For instance, Moroccan students can be instrumentally motivated to learn English just for entertainment purposes such as watching English movies and TV programs or listening to songs.

Table 11: Extrinsic motivation

\begin{tabular}{|c|c|c|c|}
\hline $\begin{array}{l}\text { Type of } \\
\text { motivation }\end{array}$ & Elements of each type & Frequency & $\%$ \\
\hline \multirow{7}{*}{ Extrinsic } & English as a source of relaxation compared to other classes & 9 & 15 \\
\hline & $\begin{array}{l}\text { Diversity of learning activities and group work in the English } \\
\text { class }\end{array}$ & 7 & 11.7 \\
\hline & Use of different methods and pedagogies in the English class & 10 & 16.7 \\
\hline & Teacher as source of motivation & 12 & 20 \\
\hline & Learning and using English because one is obliged to do so & 14 & 23.3 \\
\hline & Associating value with learning English & 45 & 75 \\
\hline & Learning English to get high grades & 1 & 1.7 \\
\hline
\end{tabular}

This qualitative study indicates that the interviewees' level of extrinsic motivation is somehow low compared to the other types of motivation. Some of the interviewees state that they enjoy the English 
class because it is characterized by the diversity of learning activities based on group work. This is clearly stated in the answer of a female interviewee specialized in Mathematics when she spontaneously says: "Yes, of course especially if there are a lot of activities in the English class such as songs and games because they help us improve our English and learn easily." One of the external factors which motivate Moroccan university EFL Science students to learn English may be the way they are taught English such as the use of games and songs in class. This means that Moroccan students prefer to learn in a comfortable and relaxed environment in which they experience learning a foreign language in a funny way without being under stress and pressure. However, some of the informants say that they learn English because they are obliged to do so. For instance, a female interviewee from Physics major confirms that “Although I said I don't like English, I would like to learn it and have a good level because I'm obliged to do so since English is the language of scientific research." Moreover, learning English to get a good grade is not much solicited as an extrinsic motivation because only few informants state that they learn English for this purpose. Another factor which best explains this extrinsic orientation in learning English is related to the feeling of obligation. That is, students feel they are obliged to learn the language in order to fulfill the academic requirements of the university or because they are in need of English for scientific reasons like doing research.

Other interesting aspects of extrinsic motivation emerge in the semi-structured interview. For instance, the majority of the informants state that they learn English because they associate certain values with the language. A female interviewee majoring in Chemistry responds in this way: “...I think it is very important because as I said before it is an international language. English never dies and it is a passport for communication with different people from different nationalities." This extrinsic inclination in learning English can also be due to the value which Moroccan students associate with learning English. They view the language as the world lingua franca which allows them to communicate with people from different countries.

Another interesting aspect of extrinsic motivation spotted in the interview is the teacher as a source of motivation. Some of the interviewees say that they are motivated if their teacher of English helps them learn the language. For instance, a male informant from Chemistry major says "I enjoy the English class, especially if I participate well or if the teacher can create a joyful atmosphere in the classroom and motivate us to learn. The English class makes me feel delighted unlike the French class in which I feel embarrassed and afraid to participate." Furthermore, the use of different methods and pedagogies in the English class is another aspect of extrinsic motivation for students to 
learn English. For example, a male interviewee from Computer Science major expresses this clearly in the following extract: "Yes certainly because the English class is different from the other classes which rely on lecturing and note-taking; this is sometimes boring. The English class, however, is lively and dynamic because there are varied activities which require interaction."

It seems, thus, that students' external motivation is not only boosted by the way they are taught English, but the teacher, as an external factor, seems also to play a crucial role in motivating or demotivating students as well. If the teacher is able to create a relaxed and dynamic atmosphere in class for students to learn without much anxiety, he/she will boost their extrinsic motivation which, if sustained, can be turned into intrinsic motivation later.

Other interviewees consider English as a source of relaxation compared to other classes which is another element of extrinsic motivation. This is why one female respondent from Physics major states: "Yes, sure I enjoy the English class because I feel relaxed and I change the routine of scientific thinking and learning. In the English class, I express myself freely and I interact with the teacher and students; something which we rarely do in the other classes."

On the whole, the results reveal that the present study participants are extrinsically motivated, though not with the same degree as integrative, intrinsic or instrumental motivation. This may be attributed to the fact that they are not much exam-oriented since they rarely learn English only to get good grades. On the other hand, they learn English either for its own sake or for utilitarian purposes (future career or furthering studies). From the findings of the current study, it can be concluded that integrative/instrumental and intrinsic/extrinsic types of motivation are placed along a continuum and the students' motivation as a psychological state fluctuates between different types depending on their needs and interests.

\section{Implications and conclusions}

Based on the findings of the present study, some pedagogical implications can be drawn to gain some insights into the curriculum development and textbook design areas as well as the teaching and learning process. These implications are as follows:

* There should be an emphasis on basing the curriculum guidelines on the language learning strategy theory. For instance, curriculum developers can encourage teachers to incorporate strategy instruction within their courses. 
* Textbook designers can produce language textbooks which include a variety of tasks that require students to use a wide range of language learning strategies.

* The textbook designers can include strategy instruction as part of the syllabus to raise both teachers' and learners' awareness of language learning strategies.

* Teachers should be aware of the existence of an unlimited variety of learning strategies and try to equip their students with the appropriate ones to acquire each skill of the language. This can be done through strategy instruction and specifically through explicit training of students into how to apply the learning strategies.

* Teachers should provide students with language tasks which motivate them to use language learning strategies and become more enthusiastic and, hence, enjoy language learning.

The findings of the present study have also triggered the researcher's interest in some possible implications for future research in the area of language learning strategies. Among these implications, there are the following:

- Further research should focus on other factors such as students' learning styles, personality traits, or language proficiency which can provide a clearer picture of LLS use by Moroccan university EFL Science students in particular and EFL students in general.

* More research should be conducted on LLSs in Morocco which combines both learners' and teachers' perceptions of LLS use with a focus on the learning strategies used by students and how they match the teaching strategies used by teachers.

* There is a need for an experimental study which tests the effect of strategy training on improving students' proficiency level in English.

* Other research instruments should be used to assess the use of LLSs besides questionnaires and interviews, including, for example, verbal protocols in order to elicit more invisible strategies that students use to mentally process language learning.

* Future research projects should try different research designs such as experimental studies, case-studies, longitudinal studies and diary-based studies in order to gain more insights into the actual use of strategies and the different factors which influence them. 


\section{References}

Anderson, N.J. "The role of metacognition in second language teaching and learning". ERIC Digest. Education Resources Information Centre.2002. Retrieved from:

https://eric.ed.gov/?id=ED463659

Anderson, N. J. "Metacognitive reading strategies increase L2 performance". The Language Teacher, 27, 20-22. 2003. Retrieved from:

https://jaltpublications.org/old_tlt/articles/2003/07/anderson?y=2003\&mon=07\&page=ander son

Bandura, A. Self-efficacy: the Exercise of Control. London: W.H. Freeman. 1997

Bonney, C.R.; Cortina, K.S.; Smith-Darden, J.P. \& Fiori, K. L. "Understanding strategies in foreign language learning: Are integrative and intrinsic motives distinct predictors?" Learning and Individual Differences, 18, (1), pp. 1-10. 2008

https://doi.org/10.1016/j.lindif.2007.11.005

Chamot, A. U. "Issues in language learning strategy research and teaching”. Electronic Journal of Foreign Language Teaching, (1), 12-25. 2004. Retrieved from: www.e- flt.nus.edu.sg

Chamot, A.U.; Barnhardt, S.; El-Dinary, P.B., \& Robbins, J. The Learning Strategies Handbook. White Plains, NY: Addison Wesley Longman. 1999

Chang, S. M. \& Huang, S. H. “Taiwanese English learners' learning motivation and language learning strategies". Proceedings of the sixteenth Conference on English Teaching and Learning in the Republic of China (pp. 111-128). Taipei: The Crane Publishing Co. 1999

Chen, W. L. "Motivation and Learning Strategies in Learning English as a Foreign Language: a case in Taiwan". Paper presented at 2000 AERA (American Educational Research Association) Annual Meeting, New Orleans, Louisiana, USA. (2000, April)

Cohen, A. D., \& Weaver, S. J. “Strategies-based instruction for second language learners”. In W. A. Renandya \& G. M. Jacobs (Eds.), Learners and Language Learning (pp.1-25). Singapore: SEAMEO Regional Language Centre. 1998 
Gardner, R. C. Social Psychology and Second Language Learning: The Role of Attitudes and Motivation. London: Edward Arnold. 1985

Griffiths, C. "Patterns of language learning strategy use". System, 31, 367- 383. 2003 https://doi.org/10.1016/S0346-251X(03)00048-4

Griffiths, C. (2006). Strategy development and progress in language learning. Prospect, 21(3), 5875. Retrieved from:

http://www.ameprc.mq.edu.au/data/assets/pdf_file/0007/229885/21_3_4_Griffiths.pdf

Khamkhien, A. "Factors Affecting Language Learning Strategy Reported Usage by Thai and Vietnamese EFL Learners". Electronic Journal of Foreign Language Teaching, 7(1), 66-85. 2010. Retrieved from: http://e-flt.nus.edu.sg/v7n12010/khamkhien.pdf

Lee, C.K. "An overview of language learning strategies". ARECLS, 7, 132-152. 2010. Retrieved from: https://core.ac.uk/download/pdf/25889647.pdf

Macaro, E. "Fourteen features of a language learner strategy". Working Paper \#4. Oxford: Department of Educational Studies, University of Oxford. 2004. Retrieved from: http://crie.org.nz/research-papers/1Ernesto_Macaro_WP4.pdf

Naiman, N.; Frohlich, M.; Stern, H. \& Todesco, A. The good language Learner. Research in Education Series, No.7, Institute for Studies in Education, Toronto: Ontario. 1978

O’Malley, J. M. \& Chamot, A. U. Learning Strategies in Second Language Acquisition. New York: Cambridge University Press. 1990

O’Malley, J.M.; Chamot, A.U.; Stewner-Manzanares, G.; Russo, R.P. \& Kupper, L. "Learning strategy applications with students of English as a second language”. TESOL Quarterly, 19(3), 557 - 584. 1985b. https://doi.org/10.2307/3586278

Oxford, R. L. "Language learning styles and strategies". In M. Celce-Murcia (Ed.), Teaching English as a Second or Foreign Language ( $3^{\text {rd }}$ Ed., pp. 359-366). Boston: Heinle \& Heinle. 2001

Oxford, R. L. Language learning motivation: pathways to the new century. Honolulu: University of Hawaii, Second Language Teaching and Curriculum Center. 1999

Oxford, R. L. Language Learning Strategies: What Every Teacher Should Know (pp.1- 191). New York: Newbury House Publications. 1990 
Oxford, R. L. \& Burry-Stock, J. A. "Assessing the use of language learning strategies worldwide with the ESL/EFL version of the Strategy Inventory for Language Learning (SILL)." System, 23(1), 1-23. 1995. https://doi.org/10.1016/0346-251X(94)00047-A

Oxford, R. L. \& Nyikos, M. "Variables affecting choice of language learning strategies by university students". The Modern Language Journal, 73 (3), 291-300. 1989. https://doi.org/10.2307/327003

Pong, G. EFL motivation and strategy use among Taiwanese senior high school learners. Unpublished Master thesis. National Taiwan University of education. Taiwan: Taipei. 2002

Politzer, R. L. and McGroarty, M. "An exploratory study of learning behaviours and their relationships to gains in linguistic and communicative competence". TESOL Quarterly, 19(1), 103- 123. 1985. https://doi.org/10.2307/3586774

Riazi, A. \& Rahimi, M. “Iranian EFL Learners' Pattern of Language Learning Strategy Use”. The Journal of Asia TEFL, 2(1), 103-129. 2005. Retrieved from: http://files.eric.ed.gov/fulltext/ED490028.pdf

Rigney, J.W. "Learning strategies: A theoretical perspective”. In O’Neil, H.F. (Jr) (Ed.). Learning Strategies (pp. 165-205). New York: Academic Press. 1978

Rubin, J. "Learner strategies: Theoretical assumptions, research history and typology". In A. Wenden \& J. Rubin (Eds.), Learner strategies in language learning (pp. 15-30). Englewood Cliffs, NJ: Prentice Hall. 1987

Rubin, J. "What the "good language learner" can teach us." TESOL Quarterly, 9(1), 41-51. 1975. https://doi.org/10.2307/3586011

Seliger, H. W. "Processing universals in second language acquisition". In F. R. Eckman, L. H. Bell, and D. Nelson (eds.), Universals of Second Language Acquisition. (pp. 36-47). Rowley, Mass.: Newbury House. 1984

Stern, H. H. Issues and Options in Language Teaching. Oxford, UK: Oxford University Press. 1992

Stern, H. H. Fundamental Concepts of Language Teaching. New York, NY: Oxford University Press. 1983 
Tam, K. Chi-Him. "A study on language learning strategies (LLSs) of university students in Hong Kong". Taiwan Journal of Linguistics, 11(2), 1-42. 2013. Retrieved from: http://tjl.nccu.edu.tw/main/uploads/11.2_______.pdf

Vigotsky, L. Interaction between Learning and Development: From Mind and Society (pp. 79-91). Cambridge, MA: Harvard University Press. 1978

Weinstein, C. E. \& Mayer, R. E. "The teaching of learning strategies". In M. Wittrock (Ed.), Handbook of Research on Teaching ( $3^{\text {rd }}$ Ed., pp. 315-327) 1986 